\title{
Identification and localization within digit and letter spans
}

\author{
MURRAY J. WHITE, Victoria University of Wellington, \\ Wellington, New Zealand
}

Subjects were required to identify and localize digits or letters from displays containing eight elements across the visual field, four elements in the left visual field, or four elements in the right visual field. Exposure duration, presentation condition, and type of material were found to affect recall. In addition, an interaction between element position and exposure duration was found for localization scores.

The present experiment was undertaken to assess the role of position when asymmetrical (left or right visual fields) presentations were randomized with symmetrical (left and right visual fields) presentations, and where scoring was based on (a) correct identification, and (b) correct localization of elements.

Various authors have found that when strings of letters are exposed to Ss at durations which prohibit eye movements, certain letter positions are recalled easier than others (i.e., have fewer errors of localization, omission, and commission), and that this recall depends on relative letter position within the strings (Bryden, 1966; Crovitz \& Schiffman, 1965; Mathewson et al, 1968).

\section{METHOD}

One hundred and twenty stimulus cards measuring $5 \times 7$ in. were prepared, on half of which appeared the capital English letters D, F, G, H, J, L, N, R, S, T, V, X, and Z (Standardgraph stencil $203 / 7$, pen 56) so that 20 cards had eight letters across the card (symmetrical letters condition), 20 cards had four letters to the right, and 20 cards had four letters to the left of center (asymmetrical letters). The digits 1-9 appeared on the remaining 60 cards, such that 20 cards had eight digits across the card (symmetrical digits), 20 cards had four digits to the right, and 20 cards had four digits to the left of center (asymmetrical digits). When viewed in a tachistoscope (of private manufacture), the symmetrical material subtended a visual angle of $5 \mathrm{deg} 44 \mathrm{~min}$; the luminance of both adapting and stimulus fields was $1.5 \mathrm{ft}-\mathrm{L}$. The elements appeared $20 \mathrm{~min}$ high and averaged $16.8 \mathrm{~min}$ wide, and had $48 \mathrm{~min}$ separating their centers. Elements were randomly chosen from the populations and assigned to positions within the strings.

Eight blocks of 15 cards were arranged so that each block consisted of 5 symmetrical and 10 asymmetrical ( 5 left, 5 right) cards, of a particular material. Within each block, cards were in a randomized presentation order. Thus, there were four blocks of letters and four blocks of digits; for each material, one block was shown at $25 \mathrm{msec}$, one at $50 \mathrm{msec}$, one at $75 \mathrm{msec}$, and one at $100 \mathrm{msec}$. The order of presentation of Blocks by Material was counterbalanced over Ss. Half the Ss received blocks in the order 25-50-75-100 msec and half in the order 100-75-50-25 msec.

Subjects were required to fixate a small centered dot (2.8-min arc) in the adaptation field and, when prepared and fixating, to press a microswitch which would expose the stimulus field. Consequent on exposure, Ss verbally reported the elements, and, at the same time, wrote them on a check-sheet in the order they were shown. Two scores were thus available: (1) an identification score (reported element present, irrespective of position), and (2) a localization score (reported element present and shown in its correct position). Viewing was binocular throughout.
Subjects were eight graduate and undergraduate students, familiar with general tachistoscopic procedure.

RESULTS AND DISCUSSION

Four separate analyses of variance were conducted on the data ( 2 Conditions by 2 Scorings). The distribution of correct identification and localization scores is shown in Fig. 1. The main effects of Conditions, Exposure, and Material were significant at the .01 level, with the exceptions of Material in the asymmetrical-localization case $(p<.05)$ and Material in the symmetrical-localization case $(.05<p<.10)$. The interaction of Exposure by Material for identification scores was significant at the .05 and .01 levels for asymmetrical and symmetrical conditions, respectively $(F=3.12, \mathrm{df}=3 / 21$; $\mathrm{F}=15.13, \mathrm{df}=3 / 21$ ). The interaction of Position by Material for localization scores was significant at the .01 level in the symmetrical conditions $(\mathrm{F}=2.29 ; \mathrm{df}=21 / 147)$.

Considering the main effects first: (1) The fourelement asymmetrical conditions had higher percentage-correct scores than the eightelement symmetrical conditions, but the mean numbers of elements correctly reported were 2.41 and 3.43 (identification) and 1.93 and 1.62 (localization), respectively. Constraints placed on recall by span of immediate memory (Sperling, 1960) undoubtedly limited the relative percentage of symmetrical conditions recall scores. (2) Increases in exposure duration seem to increase amount of detail perceived in the visual field, and consequently, the number of elements available for recall. (3) That the digit population was slightly smaller than the letter population and digits were more readily accessible from memory for comparison with test elements than were isolated letters seems to account for the higher digit scores. With few exceptions, localization scores were lower than identification scores, indicating the relative task-difficulty of identifying and localizing, vis-a-vis identifying alone (cf. Crovitz et al, 1966).

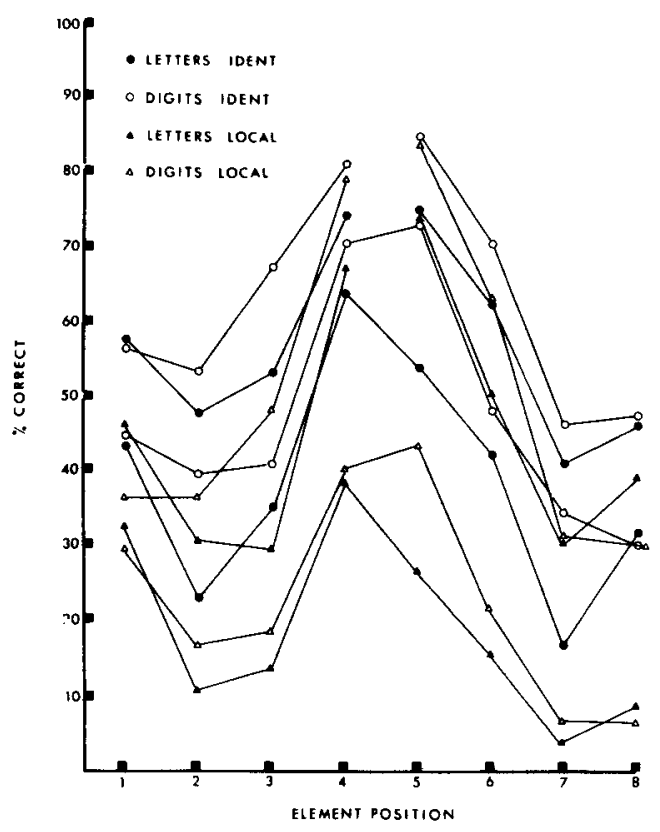

Fig. 1. Percentage of letters and digits correctly identified and localized. Broken graphs: asymmetrical conditions; umbroken graphs: symmetrical conditions. 


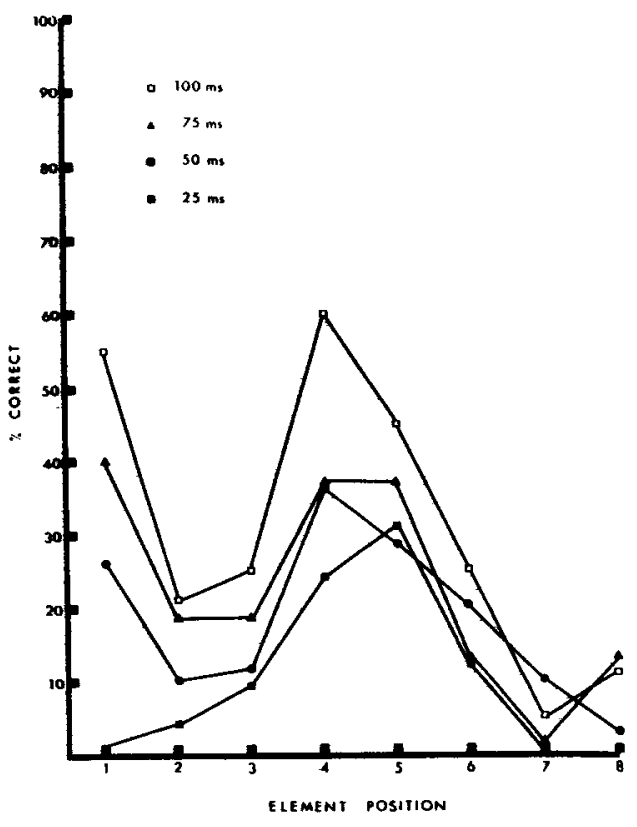

Fig. 2. Interaction of Exposure by Element Position for localization scores in the symmetrical condition.

The critical interaction of Exposure by Position for localization scores in the symmetrical condition is shown in Fig. 2. The data indicate that as exposure increases, elements in the left periphery of the visual field are recalled more readily. What is happening here, it seems, is that increasing exposure allows the left-right scan to start further at the left. The percentages of elements correctly localized in the symmetrical condition from Position 1 were: $1(25 \mathrm{msec})$, $26(50 \mathrm{msec}), 40(75 \mathrm{msec})$, and $55(100 \mathrm{msec})$. The mean left-right order of report (Bryden, 1966) also increased over exposure: $.71(25 \mathrm{msec}), .74(50 \mathrm{msec}), .79(75 \mathrm{msec})$, and $.86(100 \mathrm{msec})$. The absence of this interaction in the analysis by identification scores can be attributed to a high degree of identification of elements but in incorrect element positions, thus cancelling any position effects.

The interaction of Exposure by Material for identification scores and the absence of same for localization scores would also indicate digits are better identified and recalled (irrespective of position) than letters, but scoring by localization reduces this discrepancy. Any response-bias and guessing, probably inherent in identification scores and expectedly greater for digits (9) than for letters (13), would also be reduced by localization criteria.

Generally, the data parallel those of Crovitz \& Schiffman (1965), Bryden (1966), and Mathewson et al (1968). The experimental conditions employed here may account for the high accuracy of the middle (4 and 5) positions relative to the extreme left position (1) not found by the authors cited. The likelihood of Ss having a set to scan from far-left to far-right throughout experimental trials, possible in the conditions employed by these authors, is reduced by randomizing asymmetrical with symmetrical presentations within trialblocks. This may also account for the clear Exposure by Position interaction for localization scores, suggested by their data (the $F$ of 2.96 with $\mathrm{df}=7 / 133$ given by Mathewson et al, would appear to be highly significant in this respect, though they state it is not significant).

\section{REFERENCES}

BRYDEN, M. P. Accuracy and order of report in tachistoscopic recognition. Canadian Journal of Psychology, 1966, 20, 262-272.

CROVITZ, H. F., \& SCHIFFMAN, H. R. Visual field and the letter span. Joumal of Experimental Psychology, 1965, 70, 218-223.

CROVITZ, H. F., SCHIFFMAN, H., LIPSCOMB, D. B., POSNICK, G., REES, J., SCHAUB, R., \& TRIPP, R. Identification and localization in the letter span. Canadian Journal of Psychology, 1966, 20, 455-461.

MATHEWSON, J. W., MILLER, J. C., JR., \& CROVITZ, H. F. The letter span in space and time. Psychonomic Science, 1968, 11, 69-70.

SPERLING, G. The information available in brief visual presentations. Psychological Monographs: General \& Applied, 1960, 74, (11, Whole No. 498),

(Continued from page 278)

inductive strategy could be applied. No evidence for such conversion was found in the present study. Huttenlocher (1962) suggested that Ss might use formal strategies which required more steps of reasoning for certain negative instance problems than for certain positive instance problems. Although this suggestion cannot be directly tested by the present data, since the present tasks are most similar to ones for which Huttenlocher hypothesizes an equal number of reasoning steps, the finding that lowered proficiency is only associated with concrete strategies does not support Huttenlocher's notion that lowered proficiency can occur for formal strategies involving increased numbers of reasoning steps.

\section{REFERENCES}

BRUNER, J. S., GOODNOW, J. J., \& AUSTIN, G. A. A study of thinking. New York: Wiley, 1956.

DENNY, J. P. Effects of anxiety and intelligence on concept formation. Journal of Experimental Psychology, 1966, 72, 596-602.

DENNY, J. P., \& BENJAFIELD, J. G. Interpretation of information that an instance is positive or negative in concept identification. Psychonomic Science, 1968, 12, 283-284.
FLAVELL, J. H. The developmental psychology of Jean Piaget. New York: Van Nostrand, 1963.

FRYATT, M. J., \& TULVING, E. Interproblem transfer in identification of concepts involving positive and negative instances. Canadian Journal of Psychology, 1963, 17, 106-117.

GLANZER, M., HUTTENLOCHER, J., \& CLARK, W. H. Systematic operations in solving concept problems. Psychological Monographs, 1963,77 (Whole No. 564).

HOVLAND, C. I., \& WEISS, W. Transmission of information concerning concepts through positive and negative instances. Journal of Experimental Psychology, 1953, 45, 175-182.

HUTTENLOCHER, J. Some effects of negative instances on the formation of simple concepts. Psychological Reports, 1962, 11, 35-42.

WICKELGREN, W. A., \& COHEN, D. H. An artificial language and memory approach to concept attainment. Psychological Reports, $1962,10,815-827$.

\section{NOTES}

1. Based on data collected for an M.A. thesis by the junior author, supervised by the senior author, and submitted to the Faculty of Graduate Studies, University of Western Ontario. This research was partially supported by National Research Council of Canada Grants APA-81 and APA-137.

2. Now at Rutgers: The State University, Newark, N. J. 